\title{
Comparison of MRCP with Intraoperative Cholangiography in Paediatric Choledochal Cyst and Biliary Atresia
}

\author{
Raashid Hamid ${ }^{1 *}$, Nisar A Bhat ${ }^{2}$, Aejaz A Baba ${ }^{2}$, Ferooz Shaheen ${ }^{3}$ and Gulzar Ahmad ${ }^{4}$ \\ ${ }^{1}$ Senior Resident, Department of Paediatric and Neonatal Surgery Skims Srinagar, Jammu and Kashmir, India \\ ${ }^{2}$ Department of Paediatric and Neonatal Surgery, Skims, Srinager, Jammu and Kashmir, India \\ ${ }^{3}$ Department of Radio diagnosis and imaging Skims Srinager, Jammu and Kashmir, India \\ ${ }^{4}$ Department of Gastroenterology Skims Srinager, Jammu and Kashmir, India
}

Received: January 20, 2017; Accepted: March 15, 2017; Published: April, 17, 2017

*Corresponding author: Raashid Hamid, Senior Resident, Department of Paediatric and Neonatal Surgery Skims Srinager, Jammu and Kashmir, India, Tel no: 9469451875; E-Mail: drraashidhamid@gmail.com

\begin{abstract}
Background: Hepatobiliary and pancreatic disorders in children are infrequent and include Duct union (APBD - union), Extra hepatic biliary atresia (EHBA), Caroli's disease, primary sclerosing cholangitis, pancreas divisum and pancreatic duct abnormalities. A range of investigations have been used for evaluation of these disorders in children ranging from sonography, HIDA Scan computed tomography, ERCP, Cholangiography and MRCP. Among these MRCP is a non-invasive investigation which has the potential to delineate the hepatobiliary pancreatic ductal system preoperatively to help surgeon in diagnosis and operative planning
\end{abstract}

Aims and objectives: The purpose of this study was to determine whether MRCP is feasible in paediatric age group patients and to look for the possible measures to optimize the pediatric MRI. Furthermore, we calculated sensitivity, specificity and accuracy of this test by comparing the results of this test with those of surgery and intra-operative cholangiogram (IOC).

Material and Methods: This study was a prospective and descriptive study between Oct - 2012 to Jan- 2015. We examined 50 consecutive children ( 28 boys and 22 girls), who were suspected of having pancreaticobiliary disease. Besides base line sonography, MRCP was performed in all patients. The findings of MRCP were compared with those of intraoperative cholangiography (IOC). HIDA was done in 20 patients with neonatal cholestsis and these results were also compared with IOC.

Results: A total of 50 children ( 7 neonates, 17 infants and 26 older children), 30 children with ductal dilatation and 20 children with cholestatic jaundice. The sensitivity, specificity and accuracy of MRCP were $50 \%, 75 \%$ and $60 \%$ respectively in detecting the APBD-union in our series. The sensitivity, specificity, accuracy, Positive predictive value and Negative predictive value of MRCP were $84.61 \%, 85.71 \%$ and $85 \%, 91.66 \%$ and $75 \%$ respectively in detecting biliary atresia. For patients with neonatal cholestasis, biliary atresia was excluded if there was visualization of normal extra-hepatic biliary system at MR cholangiography. The sensitivity ,specificity, positive predictive valve ,negative predictive valve and accuracy of $99 \mathrm{mTc}-\mathrm{HIDA}$ was $69.23 \%, 71.42 \%, 81.8 \%, 61.1 \%$ and $70 \%$ respectively. Sedation was required in patients in infants in 10 instances for an optimal MRCP in children. Out of 24 patients having age $<1$ year, oral Trichlorphos @ 50-100 mg/Kg was required in 6 instances and intravenous diazepam was needed in 4 patients.

Conclusion: MRCP is effective in delineated choledochal cyst type, and helpful in diagnosing related pancreaticobiliary anomalies, such as APBD-union. But more evaluation needs to be done to assess the MRCP ability to detect APBD - union. Furthermore from our preliminary results, we can conclude that BA can be ruled out if complete extrahepatic bile duct (EHBD) is delineated on MRCP. If EHBD is partially visualized, BA cannot be ruled out because atresia may involve only one part of EHBD. Non - visualization of entire EHBD is suggestive but is not synonymous of BA.

Key Words: Choledochal Cyst (CDC); Anomalous Pancreaticobiliary Ductal Union (APBD union); Magnetic resonance cholangiopancreaticography (MRCP); Intra-operative cholangiogram (IOC)

\section{Introduction}

CDC is a congenital anomaly involving cystic dilatation of various ducts of biliary tree. Proper imaging plays an essential role in preoperative planning. Ultrasonography, computed tomography (CT) and radionuclide scintigraphy may be used initially for diagnosis. However, these techniques are inadequate for delineating the exact pathologic anatomy and APBJ. Endoscopic retrograde cholangiopancreatography (ERCP) is the standard for diagnosis of APBD- union. Intra operative cholangiogram under fluoroscopy is the best investigation after ERCP that delineates the pancreatico-biliary tree and is considered the confirmatory test in biliary atresia. IOC is the most frequently applied technique for intra-operative assessment of the pancreaticobiliary system. It presents high visualization rate of PBM but low detection rate of biliary variants in children with CDC. [1] Although ERCP 
is the standard of reference for imaging the pancreaticobiliary system but there are specific advantages of MRCP over ERCP. We speculate that MRCP may replace diagnostic laparotomy and intra-operative cholangiography in jaundiced neonates in whom no bowel excretion is seen in cholescintigrams. Keeping in view the non-invasive nature of MRCP, this study was undertaken to look for usefulness of MRCP in neonatal cholestasis (EHBA, CDC, CBD anomalies). Furthermore MRCP was correlated with IOC findings.

The purpose of this study was to determine whether MRCP is feasible in paediatric age group patients and to look for the possible measures to optimize the pediatric MRI. Furthermore, we calculated sensitivity, specificity and accuracy of this test by comparing the results of this test with those of surgery and intraoperative cholangiogram (IOC).

\section{Subjects and Methods}

This study was a prospective and descriptive study between Oct - 2012 to Jan - 2015. We examined 50 consecutive children (28 boys and 22 girls), who were suspected of having pancreaticobiliary disease. Children diagnosed with choledochal cyst on ultrasound with or without jaundice and Persistent cholestasis in infancy. The patients were admitted in our department. Detailed history and examination was performed. After informed consent, these patients were subjected to MRCP for evaluation of hepatobiliary ductal abnormalities and relationship between biliary and pancreatic ductal system. In babies with persistent Cholestasis of infancy, 99mTc-HIDA scan was performed.

In patients aged 6 years and below, we used "sleep debt technique" devised by us, wherein parents were advised to discourage early sleeping and late rising of the child on the night preceding the MRI examination; this resulted in a significant sleep debt of 4 to 5 hours. On the next day, the child was provided milk /breast feed in the MRI suite and was encouraged to go to sleep which helped enough to allow an interrupted MR examination. Children between 6 months to 6 years were sedated with oral Trichlorphos $\quad(50-100 \mathrm{mg} / \mathrm{Kg} /$ body weight and children $<6$ months were sedated by intravenous injection of Midazolam $0.5 \mathrm{mg} / \mathrm{Kg} /$ body weight when required.

\section{IOC Techniques}

After laparotomy and identification of CDC, IOC was performed by taking per string suture on GB fundus and injecting 76\% Compound Diatrzoate Meglumine (diluted to half strength with normal saline). In case dye was seen going into the duodenum, next step was to clamp the duodenum and inject dye in head down position to delineate the proximal ductal system. The findings were documented on X-ray films (from the front to the posterior axis)

\section{MR Imaging technique}

All MR imaging examination were performed on 1.5-Tesla superconducting unit (Magnetom Avanto Siemens,
Erlangen, Germany), using a phased array body coil. We acquired a $\mathrm{T}_{1}$ weighted fast low angle short FLASH sequences (TR/TE, $150 / 4.8 \mathrm{mSec}$ : flip angle, $75^{\circ}$ acquisition matrix and $\mathrm{T}_{2}$ weighted turbo spin-echo sequence) 2000/120: echo train length 15: acquisition matrix. 128 x 256: scan time 14 seconds to localize biliary and pancreatic tree.

Magnetic resonance cholangiopancreaticography (MRCP) was performed using Fourier acquisition with single shot turbo spin echo (HASTE) sequences. All images were acquired without breath holding. Aware of results of sonography, we initially performed HASTE- sequence MRCP with acquisition of single slice at a slice thickness of 20-25 mm. MRCP at a thinner slice thickness of 3-5 mm was then performed in all patients to examine the details of response of interest. In all patients, coronal and oblique projections were acquired. The total imaging time for all examinations was within 15 minutes.

\section{Evaluation of IOC and MRCP Images}

Consultant radiologist evaluating the MRCP images were blinded to patient's clinical records and laboratory data. All the MRCP and IOC images were analysed and discussed in combined radio-surgical meet. The following criteria were defined to interpret the MRCP findings. Diagnostic criteria for biliary atresia were adapted from Bill et al. [2] Biliary atresia (BA) was diagnosed if any portion of the extra hepatic central biliary duct or common bile duct could not be delineated, regardless of whether the gallbladder was presented.

\section{Statistical Method}

Statistical analysis was performed using the Statistical Product and Service Solutions version 13 (SPSS Inc., Chicago, IL, USA) software. The categorical variables of the study have been shown in terms of frequency and percentages. The continuous variables of the study in terms of descriptive statistics like mean \pm SD. The accuracy of the test has been shown in terms of sensitivity, specificity, Positive predictive value, negative predictive value and likelihood ratio. The Chi - square tests have been used to analyse the data. P-value less than 0.05 were considered significant. The appropriate Statistical charts have been used to present the data.

\section{Results}

In this study, a total of 50 children were included. Average age of patients with CDC was $4.42 \pm 2.43$ years with a range between 6 months to 12 years. There were 20 males and 10 female patients. Most common presentation of CDC in our series was pain abdomen in $16(53.33 \%)$ cases followed by pain abdomen with jaundice in 7 (23.33\%) and incidental finding in $7(23.33 \%)$ cases. Forty $(86 \%)$ children had hepatobiliary anomaly, which included CDC in 30 patients APBD-union in 18 and without APBD-union in 12 patients) and EHBA in 13 patients and 7 babies had normal hepatobiliary anatomy. Dilatation of the biliary tract was revealed by MRCP in all 30 patients with CDC. The level of dilatation determined on MRCP images corresponded with the results of surgery/IOC in all the 30 cases. In 12 out of 30 patients, anomalous connections between pancreatic and 
biliary ducts were present and were picked on MRCP images. MRCP determined CDC in 30 patients, which included 24 Type -I and 6 cases of Type- IV CDC. Stones were located in CDC in three instances which were revealed on pre- operative MRCP also.

MRCP demonstrated the type of anomalous pancreaticobiliary ductal union (APBD-union) in 12 patients with age range between $2-10$ Years and mean age of $5.99 \pm 2.374$ ). In 9 of these 12 patients, the anomalous pancreaticobiliary ductal union revealed by MRCP was concordant with those identified by surgery / intra-operative cholangiography. In 3 patients, the anomalous pancreaticobiliary ductal union could not be confirmed by surgery/intra-operative cholangiography (IOC) probably because of poor image qualities or non opacification of the pancreatic duct. MRCP did not reveal anomalous pancreaticobiliary ductal union in 18 patients who had age range between 6 months -12 years ( mean age $3.22 \pm 2.67$ ) had markedly dilated choledochal cyst (Type-I - 11 patients and Type-IV - 7 patients ). Out of 18 patients in whom MRCP findings were not suggestive of APBD-union, 9 of these patients, the anomalous pancreaticobiliary ductal union was confirmed by IOC (4-Type -I; 5-Type-IV), after resection of the choledochal cyst. In the remaining 12 patients IOC/surgery failed to depict the anomalous pancreaticobiliary ductal union.

Sensitivity, specificity and accuracy of MRCP in delineating anomalous pancreaticobiliary ductal union were $50 \%, 75 \%$ and $60 \%$ respectively. Positive predictive value (PPV) of MRCP in delineating anomalous pancreaticobiliary ductal union $75 \%$. Negative predictive value (NPV) of MRCP in delineating anomalous pancreaticobiliary ductal union was 50 $\%$. APBD -union was revealed in 8 patients with Type- I CDC whereas this union was not visible in 8 patients with Type -IV-a CDC. IOC revealed anomalous pancreaticobiliary ductal union in 18 patients only. Mean ALP level in our CDC patients was 98.84 IU/l with a range of 35-300 IU/L. In our study average size of CDC was $3.290 \mathrm{~cm} \pm 0.514 \mathrm{~cm}$ (range $1.6-10 \mathrm{cms}$ ).

Twenty neonates and infants who had neonatal cholestatic jaundice were included in this study. Age range was between 20 days and 76 days, with a mean age of $46.45 \pm 15.65$ days. They included 13 males and 7 female neonates and infants. (Table: 10) There were 13 male and 7 female babies. The mean GGT levels were $226.85 \mathrm{u} / \mathrm{L}$ with a range between $20-543 \mathrm{u} / \mathrm{L}$. Average sizes of GB was $2.39 \pm 1.9 \mathrm{cms}$ (range $0.8-4.3 \mathrm{cms}$ ). IHD was seen in 11 cases, CHD in 8 and CBD in 8 babies. The overall diagnostic accuracy was $50 \%$.

In our study ${ }^{99} \mathrm{mTc}$-HIDA scan was performed in all the cases of neonatal cholestasis of infancy. In all cases of EHBA, findings were confirmed on laparotomy and intra- operative cholangiography. Two patients were diagnosed by IOC/ Surgical exploration as having Type- I biliary atresia; in which the distal bile duct was atretic and the common hepatic duct, gallbladder, and cystic duct were normal. Three patients were diagnosed by IOC, Surgical exploration as having Type -II biliary atresia; in which the common hepatic duct was atretic at different levels, whereas the common bile duct, cystic duct, and gallbladder were patent or atretic. Eight patients were diagnosed by IOC/Surgical exploration as having Type -III biliary atresia; in which the entire extrahepatic biliary system, including the common hepatic duct, gallbladder, and common bile duct, was atretic.

Of the 12 patients whose MRCP findings were interpreted as having biliary atresia, 7 patients were confirmed as to have EHBA by intra-operative cholangiography (IOC)/ surgical exploration and 5 patients were confirmed as having no features of BA. Of the 8 patients whose MRCP findings were not consistent with EHBA. IOC/ Surgical exploration was used as the diagnostic gold standard for BA. The sensitivity, specificity, accuracy, positive predictive value (PPV), negative predictive value (NPV) of the MRCP was 84.61\%, 85.71\%, $85 \%, 91.66 \%$ and $75 \%$ respectively. [Table 1 ], [Table 2 ], [Table 3 ], [Table 4 ], [Table 5 ], [Table 6 ], [Table 7 ], [Table 8 ], [Table 9 ], [Table 10 ], [Table 11] and [Figure1], [Figure2], [Figure 3], [Figure 4], [Figure 5], [Figure6], [Figure 7], [Figure 8], [Figure 9], [Figure 10], [Figure 11].

\begin{tabular}{|l|l|l|}
\hline \multicolumn{3}{|l|}{ Table 1: Distribution of age in Choledochal cyst patients } \\
\hline Group & Number & Percentage \\
\hline 0-6 months & 2 & 6.66 \\
\hline 7 - 12 months & 2 & 6.66 \\
\hline 13 months - 2 years & 4 & 13.33 \\
\hline 2 years-5 years & 14 & 46.66 \\
\hline 6 years-10 years & 7 & 23.33 \\
\hline >10 years & 1 & 3.33 \\
\hline Total & 30 & 100 \\
\hline
\end{tabular}

Table 2: Distribution of patients according to the ductal anomaly

\begin{tabular}{|c|c|c|}
\hline \multicolumn{2}{|c|}{ Total no of patients included in the study } & 50 \\
\hline \multicolumn{2}{|c|}{ Patients with ductal abnormalities } & 43 \\
\hline \multirow{2}{*}{ CDC $(n=30)$} & CDC with APBD- union & 18 \\
\cline { 2 - 3 } & CDC without APBD -union & 12 \\
\hline \multirow{2}{*}{$\begin{array}{c}\text { Infantile Cholestasis } \\
\text { (IC) }(\mathrm{n}=20)\end{array}$} & $\begin{array}{c}\text { EHBA } \\
\text { Cholestasis due to causes other } \\
\text { than EHBA }\end{array}$ & 7 \\
\hline
\end{tabular}

Table 3: Visualization rates of CDC, APBD -union, Biliary and Nonbiliary atresia

\begin{tabular}{|c|c|c|c|}
\hline & MRCP & $\begin{array}{c}\text { IOC/ } \\
\text { Surgery }\end{array}$ & $\begin{array}{c}\text { P- } \\
\text { value }\end{array}$ \\
\hline CDC & $\begin{array}{c}(100 \%) \\
30 / 30\end{array}$ & $\begin{array}{c}(100 \%) \\
30 / 30\end{array}$ & - \\
\hline APBD -union & $(40 \%)$ & $(60 \%)$ & 0.121 \\
\hline Biliary atresia & $12 / 30$ & $18 / 30$ & 0.744 \\
\hline $\begin{array}{c}\text { Cholestasis due to causes } \\
\text { other than EHBA }\end{array}$ & $(40.00 \%)$ & $(65.00 \%)$ & \multirow{2}{*}{$(3 / 20$} \\
\hline
\end{tabular}


Table 4: Table showing type of CDC on MRCP

\begin{tabular}{|c|c|c|}
\hline Type of CDC & Number & Percentage \\
\hline Type- IV & 6 & 20 \\
\hline Type-I & 24 & 80 \\
\hline Total & 30 & 100 \\
\hline
\end{tabular}

Table 5: Correlation between MRCP findings with Intra-operative cholangiogram (IOC)/surgery findings

\begin{tabular}{|c|c|c|c|c|}
\hline & \multicolumn{3}{|c|}{ MRCP } & $\begin{array}{c}\text { Total } \\
\text { Count }\end{array}$ \\
\hline \multirow{2}{*}{$\begin{array}{c}\text { IOC /SURGERY } \\
\text { (as gold } \\
\text { standard) }\end{array}$} & $\begin{array}{c}\text { APBD- } \\
\text { union }\end{array}$ & $\begin{array}{c}\text { No-APBD- } \\
\text { union }\end{array}$ & \\
\cline { 2 - 5 } & $\begin{array}{c}\text { APBD- } \\
\text { union }\end{array}$ & 9 & 9 & 18 \\
\cline { 2 - 5 } & $\begin{array}{c}\text { No-APBD- } \\
\text { union }\end{array}$ & 3 & 9 & 12 \\
\hline \multirow{2}{*}{ Total Count } & 12 & 18 & 30 \\
\hline
\end{tabular}

Table 6: Table showing age of the patients with cholestasis

\begin{tabular}{|c|c|c|}
\hline Range (days) & Number & Percentage \\
\hline $20-30$ & 4 & 20 \\
\hline $31-40$ & 3 & 15 \\
\hline $41-50$ & 5 & 25 \\
\hline $51-60$ & 3 & 15 \\
\hline $61-70$ & 4 & 20 \\
\hline $71-80$ & 1 & 5 \\
\hline Total & 20 & 100 \\
\hline
\end{tabular}

Table 7: Table showing GGT levels in patients with cholestasis

\begin{tabular}{|c|c|c|}
\hline Range (u/l) & Number & Percentage \\
\hline $0-100$ & 6 & 20 \\
\hline $101-200$ & 4 & 13.33 \\
\hline $201-300$ & 5 & 16.33 \\
\hline $301-600$ & 5 & 16.33 \\
\hline Total & 20 & 100 \\
\hline
\end{tabular}

Table 8: Duct visibility on MRCP in patients with cholestasis

\begin{tabular}{|c|c|c|}
\hline Duct & Visible & Invisible \\
\hline IHD & 11 & 9 \\
\hline CHD & 8 & 12 \\
\hline CBD & 8 & 12 \\
\hline
\end{tabular}

Table 9: Comparison of USG findings With Intra-operative Cholangiography (IOC) findings / surgical exploration

\begin{tabular}{|c|c|c|c|c|}
\hline & \multicolumn{3}{|c|}{ IOC /Surgery as Gold Standard } & Count \\
\hline \multirow{2}{*}{$\begin{array}{c}\text { Ultrasonography } \\
\text { (USG) }\end{array}$} & $\begin{array}{c}\text { Features } \\
\text { of Biliary } \\
\text { atresia }\end{array}$ & $\begin{array}{c}\text { No } \\
\text { features } \\
\text { of Biliary } \\
\text { atresia }\end{array}$ & \\
\cline { 2 - 5 } & BA & 9 & 6 & 15 \\
\cline { 2 - 5 } & $\begin{array}{c}\text { No features } \\
\text { of BA }\end{array}$ & 4 & 1 & 5 \\
\hline Count & 13 & 7 & 20 \\
\hline
\end{tabular}

Table 10: Table showing distribution of the type of biliary atresia on IOC/Surgery

\begin{tabular}{|c|c|c|c|}
\hline \multicolumn{2}{|c|}{$\begin{array}{c}\text { Classification of } \\
\text { Biliary Artesia }\end{array}$} & No \\
\hline Type-A & Type -III & $\begin{array}{c}\text { Entire extrahepatic central biliary ducts } \\
\text { (right, left, and common hepatic ducts) } \\
\text { and common bile duct were not visible }\end{array}$ & 8 \\
\hline Type-B & Type -II & $\begin{array}{c}\text { Common hepatic duct was not visible, } \\
\text { whereas the common bile duct, cystic } \\
\text { duct, and gallbladder were visible }\end{array}$ & 3 \\
\hline Type-C & Type-I & $\begin{array}{r}\text { Distal bile duct was atretic and CHD, GB, } \\
\text { cystic duct were normal }\end{array}$ & 2 \\
\hline
\end{tabular}

Table 11: Comparison of MRCP findings With Intra-operative Cholangiography (IOC) findings/surgical exploration

\begin{tabular}{|c|c|c|c|c|}
\hline & \multicolumn{3}{|c|}{ MRCP } & Count \\
\hline \multirow{3}{*}{$\begin{array}{c}\text { IOC /SURGERY } \\
\text { ( As Gold } \\
\text { Standard) }\end{array}$} & & $\begin{array}{l}\text { Biliary } \\
\text { atresia }\end{array}$ & $\begin{array}{c}\text { No } \\
\text { features } \\
\text { Biliary } \\
\text { atresia }\end{array}$ & \\
\hline & $\begin{array}{l}\text { Biliary } \\
\text { atresia }\end{array}$ & 11 & 2 & 13 \\
\hline & $\begin{array}{c}\text { No } \\
\text { features } \\
\text { of Biliary } \\
\text { atresia }\end{array}$ & 1 & 6 & 7 \\
\hline Count & & 12 & 8 & 20 \\
\hline
\end{tabular}




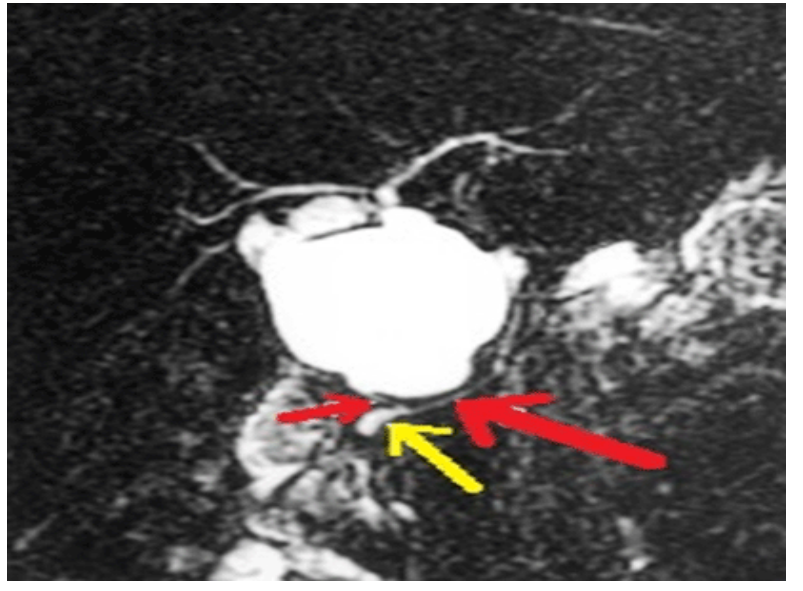

Figure 1:MR cholangiopancreatographic image in a 7 year old female child with a Type -I choledochal cyst with Abnormal pancreaticobiliary duct -union (Yellow arrow), angle between distal common bile duct (short red arrow) and pancreatic duct (long red arrow)

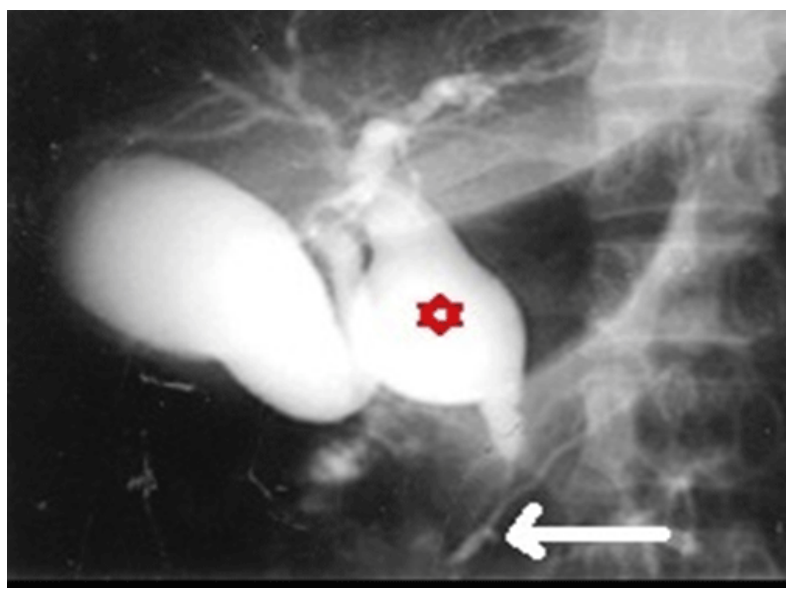

Figure 2: IOC showing Type- I CDC (star) with long common channel (APBD - union) - white arrow

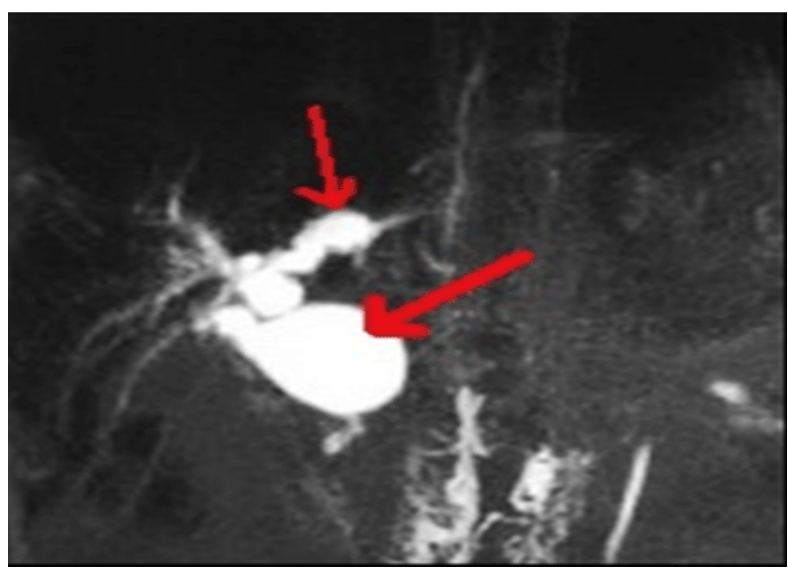

Figure 3: MRCP showing Type-IV CDC in an 11 year old child with both intrahepatic (Thin arrow) and extrahepatic duct dilatation (Thick arrow)

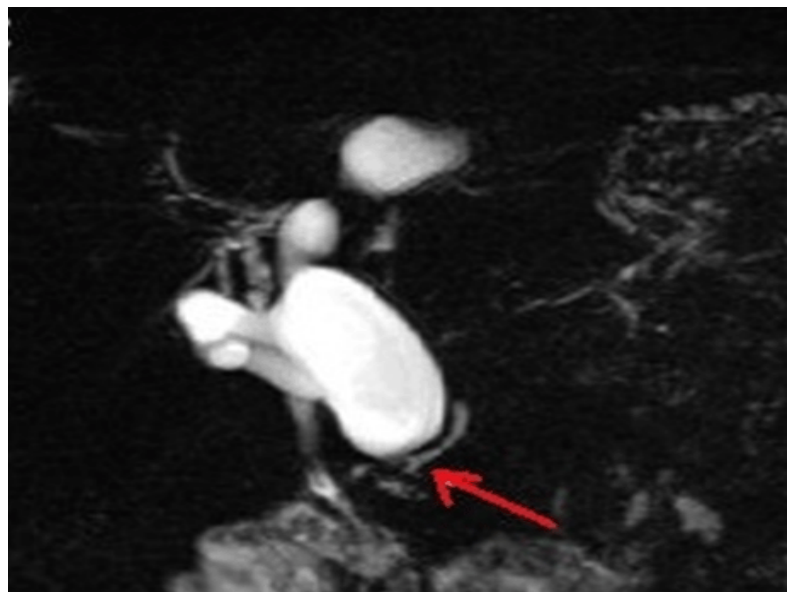

Figure 4: IOC showing Type- IV choledochal cyst with APBD - union (Red arrow)

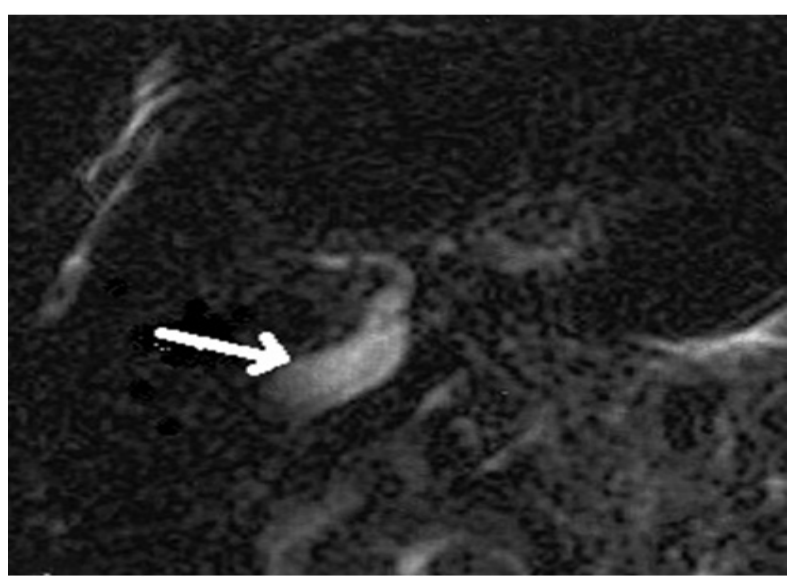

Figure 5: MRCP in a 54-day-old baby with biliary atresia does not show any extrahepatic bile ducts. Except gallbladder (white arrow)

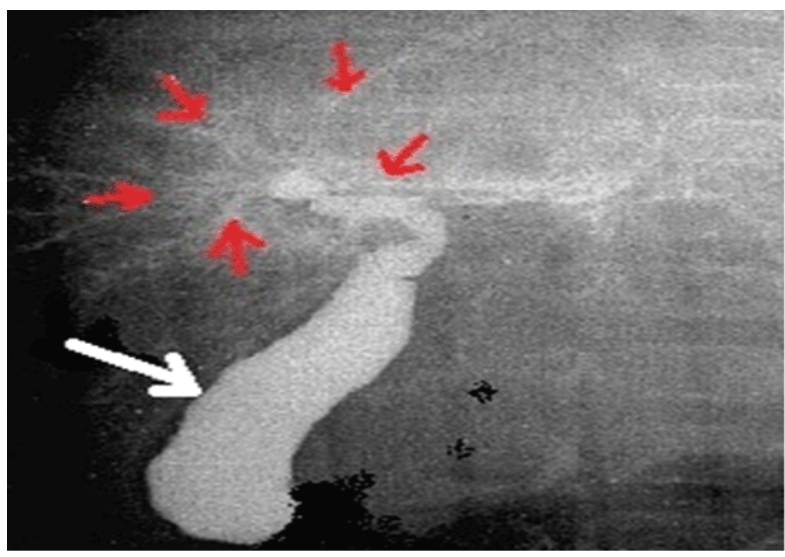

Figure 6: MIOC in same patient (Type- I biliary atresia) where MRCP failed to depict the hypoplastic intrahepatic ductules (red arrows), which are visible at intra-operative cholangiography GB-gallbladder (White arrow)

Citation: Raashid Hamid, Nisar A Bhat, et.al. (2017) Comparison of MRCP with Intraoperative Cholangiography in Paediatric Choledochal Cyst and Biliary Atresia. Gastroenterol Pancreatol Liver Disord. 4(4):1-9. DOI: http://dx.doi.org/10.15226/2374-815X/4/4/00195 


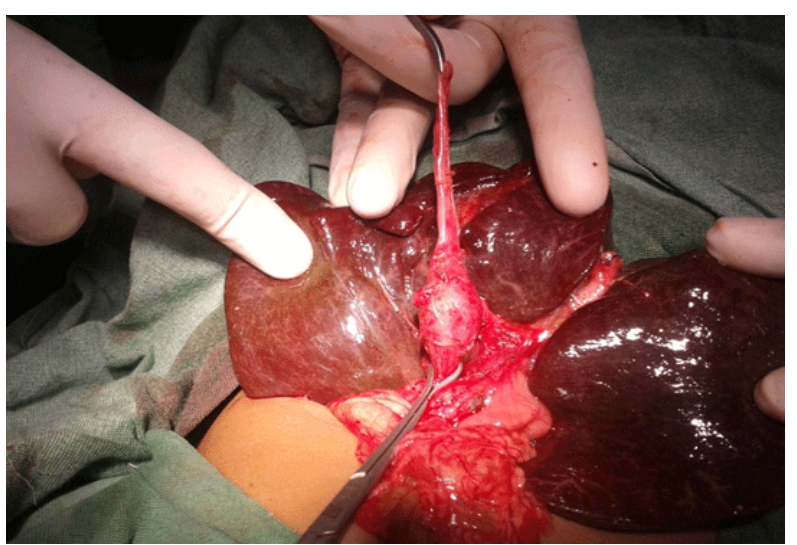

Figure 7: Infantile choledochal cyst lifted off the portal vein

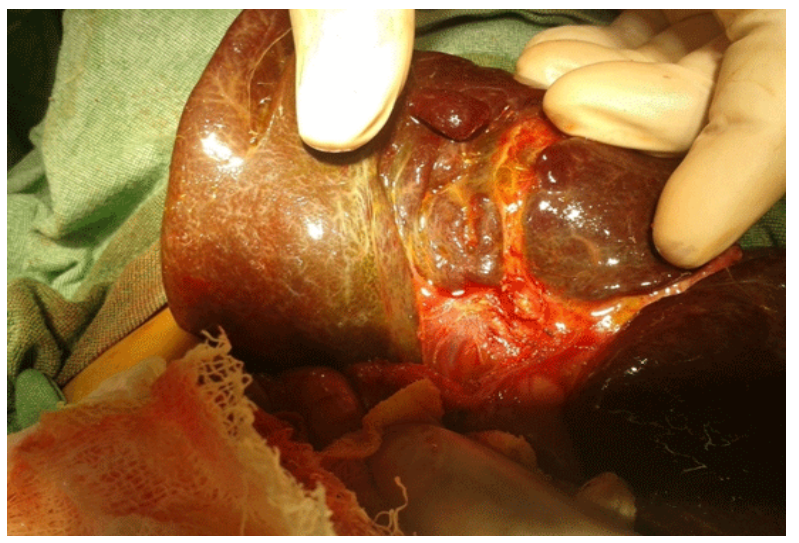

Figure 8: Portal structures after excision of choledochal cyst

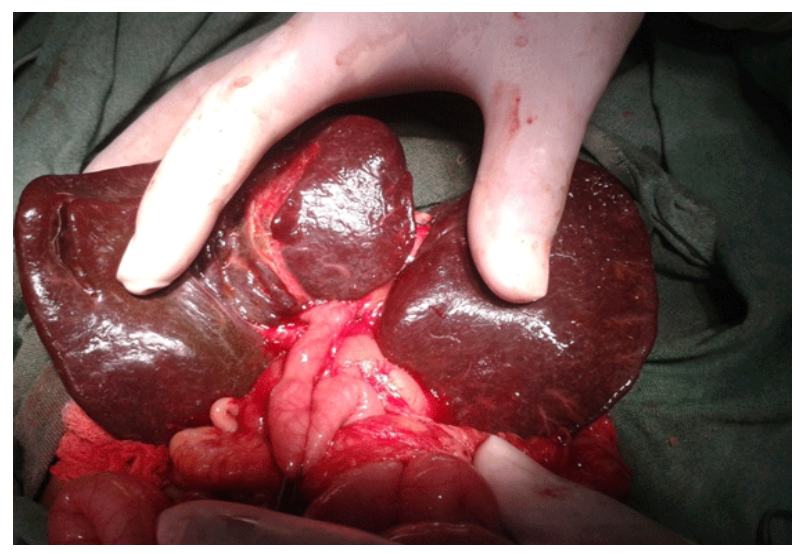

Figure 9: Hepatico-jujunostomy completed

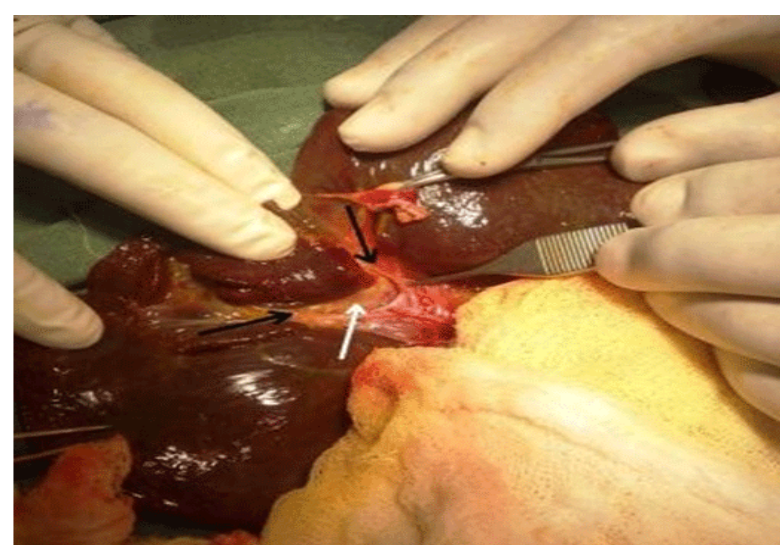

Figure 10: completed portal dissection in a case of biliary atresia .Black arrows right and left extent of dissection. Portal plate (white arrow)

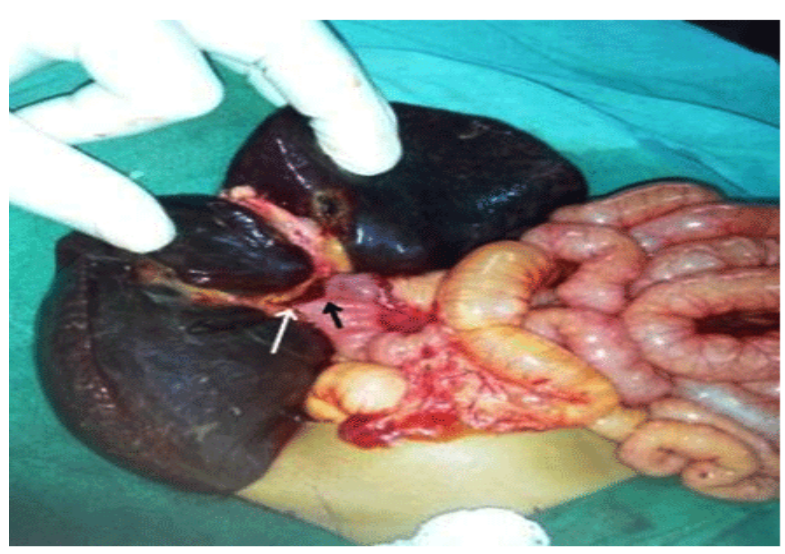

Figure 11: Portoenterostomy being performed. Jejunum (Black Arrow)

\section{Discussion}

Neonatal cholestasis is a very commonly encountered problem in Children but fortunately it is usually associated with non surgical pathology. Ultrasonography is considered as the first screening tool for all the patients of neonatal cholestasis [3]. Technique development offers a variety of algorithms for surveillance of biliary and pancreatic structures including intra-operative cholangiogram (IOC), MRCP and CT Cholangiopancreaticography [4]. Differentiation of biliary atresia (BA) from infantile hepatitis (IH) remains a common diagnostic problem because both have similar clinical presentation such as jaundice, pale stools and hepatomegaly. Patients with BA require early surgical intervention at best within two months of age before liver cirrhosis sets in. Laparotomy and intra operative cholangiography can provide direct and definitive diagnosis. The therapeutic methods for BA and IH are completely different: the former is treated with surgical therapy, including the Kasai operation or liver transplantation, as early as possible, whereas the latter is treated with medical therapy.

Citation: Raashid Hamid, Nisar A Bhat, et.al. (2017) Comparison of MRCP with Intraoperative Cholangiography in Paediatric Choledochal Cyst and Biliary Atresia. Gastroenterol Pancreatol Liver Disord. 4(4):1-9. DOI: http://dx.doi.org/10.15226/2374-815X/4/4/00195 
Mean age of presentation in CDC patients was $4.42 \pm$ 2.43 range 6 months -12 years, WHICH WAS similar to reported by authors like Todani et al and de Vries et al [5,6]. Most common presentation of CDC in our series was pain abdomen in 16 $(53.33 \%)$ cases followed by pain abdomen with jaundice in 7 (23.33\%) and incidental finding in $7(23.33 \%)$ cases, similar presentation was reported by. [7] The classical triad of abdominal pain, lump and jaundice is not common in a series of CDC by authors like de Vries et al and Lee et al [6,8]. Twenty (80\%) of patients had Type- I CDC and 6 (20\%) cases had Type- IV cysts. These findings were similar to observations made by deVries JS et al, Jordan PH et al [6,9]. In our series, 28 patients of CDC were picked up on ultrasonography as cystic lesions of the biliary tree. Moreover it could not differentiate CDC from cystic biliary atresia, this limitation of USG was observed by other authors like Chin $\mathrm{H} \mathrm{M}$ et al [10]. In our study average size of CDC was $3.290 \mathrm{~cm} \pm$ $0.514 \mathrm{~cm}$ (range $1.6-10 \mathrm{cms}$ ). It has been suggested that there is a $97 \%$ confidence of choledochal cyst when the diameter of the common bile duct is greater than $1 \mathrm{~cm}$, which was comparable to observations drawn from our series [8] .

Out of 20 cases of cholestasis, 99mTc -HIDA scan was suggestive of BA in 11 cases. In 9 cases HIDA was not suggestive of BA. The sensitivity and specificity of scintigraphy in detecting obstruction range from $83 \%$ to $100 \%$ and from $33 \%$ to $100 \%$, respectively [11]. Moyer et al study observed that scintigraphy had sensitivity and a specificity of $88.24 \%$ and $45.71 \%$ for diagnosing BA [11]. The accuracy of $99 \mathrm{mTc}$-HIDA scan in our series was comparable to the data reported by Lin et al. [12] and Nadel [13], but higher than that by Gupta et al [14]. It is likely that the discrepant results between our series and across other studies may have arisen due to the variations in radiotracer used, premedication practices, imaging protocol, interpretative criteria, study timing (patient age), and operator experience. MRCP has developed rapidly over past recent past. Its potential application in paediatrics has followed the promising results in adult biliary disorders. We used two dimensional, long acquisition turbo spin sequences. This has been shown to be superior to gradient echo sequence in visualizing the biliary tree [15]. The type and extent of CDC determined by the MRCP correlated (100\%) well with the findings IOC in all the 30 patients, this observation was same $(100 \%$ correlation between the extent of CDC determined by MRCP and IOC) as reported by Kim et al [16]. Abnormal pancreaticobiliay duct union could be delineated by MRCP in 12 cases (40\%) out of 30 choledochal cyst patients. Our findings were similar to that reported by authors like Huang S J et al [3], Anupindi S A et al [17] and Kim et al [16].

In our study, the sensitivity, specificity \& accuracy of MRCP in delineating anomalous pancreaticobiliary ductal union was $69.23 \%, 82.35 \%, \& 76.66 \%$ respectively. In 12 (60\%) of the twenty patients in a study by Kim et al [16] APBD-union was clearly visible on MRCP. One reason for this discrepancy could be greater proportion (80\%) of type I CDC in our study patients, which decreases the chances of visualization of APBD - union due to the size of the cyst. Mean age of patients in whom ABPD union was found was higher than patients in whom this APBD -union could be delineated $(5.99 \pm 2.374$ years v/s $3.22 \pm 2.776$ years). This finding has also been endorsed by authors like Kim et al [16].

Results of previous study undertaken to determine whether MRCP can depict APBD- union associated with choledochal cyst has not been consistent [18]. These differences may be due to different age of patients and imaging techniques. In a study by Clan et al, APBD- union was not delineated in MRCP using 2-0 turbo fast spin-echo sequence with the maximum intensity-projection techniques. However, in paediatric patients, MRCP with half fournier acquisition of a single shot fast spin echo might increase the sensitivity of anomalous pancreaticobiliary duct union detection [19]. APBD -union was mainly seen in TypeI choledochal cyst, however to see a correlation between type of choledochal cyst and APBD -union was not possible due less number of the cases in our series, which is similar to that reported by Kamisawa et al [20].

Early diagnosis and younger age at time of surgery afford the patients with BA a higher likelihood of a relatively good outcome. Our preliminary data suggested that MRCP in small infants can provide images of the CBD and CHD. Although IOC can provide a direct definitive diagnosis, it is undesirable if alternative techniques are available. Furthermore, many reports have suggested that MRCP is a well established non-invasive modality for visualizing the biliary system, including the first branch of the intrahepatic biliary ducts, extrahepatic bile ducts, and gallbladder [21]. In our study, however, the first branch of the intrahepatic bile ducts was not visible on MRCP images but the main intrahepatic ducts were visible in 11 cases in cholestasis patients. This lack of visibility may have resulted from insufficient bile or the smaller diameter of the biliary duct in neonates and infants being too small. Thus, we used the visibility of the extrahepatic biliary ducts on MRCP images as the diagnostic criterion for nonBA. In contrast, we considered the absence of any portion of the extrahepatic biliary ducts as the diagnostic criterion for BA.

In our study of MRCP in neonatal cholestasis of infancy, 2 false positive cases were reported. A false positive diagnosis of biliary atresia in an infant with sclerosing cholangitis, in whom MRCP could not show extrahepatic bile ducts because of its small calibre, was reported by Guband et al [13]. Although it has been reported that a small gall bladder by MRCP can be considered highly suggestive of biliary atresia, [22] Matos et al states that biliary atresia could be ruled out if the extrahepatic bile duct is completely identified at MRCP [23]. In our study MRCP had a sensitivity, specificity and accuracy of $84.61 \%, 85.71$ and $85 \%$ respectively , which was similar sensitivity (85\%) to that reported by Yang et al [18] higher than reported by Nortan et al [24].

There are problems of motion induced by respiration, bowel peristalsis, and inadequate sedation which is also a major cause of failed examination. Nonetheless, it is plausible to visualize ducts as small as $1 \mathrm{~mm}$ in diameter; due to improvement in coil technology, increased speed of acquisition, refinements in respiratory compensation techniques that reduce motion artefacts and newer sequence $[25,26]$. Paediatric MR cholangio-pancreatography needs to be tailored to different body sizes and ages. The first 
step toward such improvement is proper coil selection. Smaller children such as neonates and infants do not need a slab thickness of more than $2 \mathrm{~mm}$. Thin section axial and coronal plane images as well as thick slabs in radiating coronal planes, should be acquired. Because neonates and infants usually have irregular breathing with ranging respiratory amplitude, 3-D FSE imaging with respiratory triggering may not be possible in many of these patients [27]. High cost, limited availability and time required for scanning are problems with MRCP, but it has the capacity to provide anatomic and pathologic details of biliary tract as demonstrated in our series. There are some problems in visualizing non dilated ducts on MRCP, especially for IHD as demonstrated in our study. Lack of signal, long reduced special resolution can make the visualization of ducts more difficult. Since it is difficult to achieve respiratory cycle with a regular rhythm and adequate amplitude in infants and small children.

\section{Sedation}

To obtain rapid and high-quality images, sedation is required for the patients who underwent MRCP. In children aged 6 years and below 'sleep debt' technique was used and was enough to make child asleep which was useful in $50 \%$ of the cases. In the remaining Children between 6 months to 6 years were sedated with oral trichlorphos $(50-100 \mathrm{mg} / \mathrm{Kg} / \mathrm{BW})$ and children $<6$ months were sedated by intravenous injection of Midazolam $(0.5$ $\mathrm{mg} / \mathrm{Kg} / \mathrm{BW}$ ). No side effects were detected in our patients. According to previous reports, however, the adverse effects of these sedative drugs included respiratory depression, airway obstruction, agitation, ataxia, vomiting, and cardiac arrhythmia. [28,29] Recently, Maitre et al. [30] reported that increased exposure to phenobarbital is associated with serious neurodevelopmental outcomes. Furthermore, chloral hydrate and phenobarbital also have limitations, such as unpredictable onset, long duration, and the lack of a reversal agent, which make them less-than-ideal sedatives.

\section{Conclusion}

Pediatric MR cholangio-pancreatographic examination is limited by small calibre ducts, poor signal, and patient motion, which creates artefact. There are problems of motion induced by respiration, bowel peristalsis, and inadequate sedation which is also a major cause of failed examination. Nonetheless, it is plausible to visualize ducts as small as $1 \mathrm{~mm}$ in diameter; due to improvement in coil technology, increased speed of acquisition, refinements in respiratory compensation techniques that reduce motion artefacts and newer sequence.

\section{References}

1. Hung MH, Lin LH, Chen DF, Haung CS. Choledochal cysts in infants and children; over a 20-year period at a single institution. Eur J Pediatr. 2011;170(9):1179-1185. doi: 10.1007/s00431-011-1429-2

2. Liu BO, Cai J, Xu Y,Peng X, Zheng H, Haung K, et al. Three Dimensional MRCP for diagnosis of biliary atresia in infants and neonates. PLoS One. 2014;9(2):e88268. doi: 10.1371/journal.pone.0088268

3. Tadokoro H, Takase M. Recent advances in choledochal cysts. OJGas.
$2012 \cdot 2 \cdot 145-154$

4. Vitellas KM, Keogan MT, Spritzer CE, Nelson RC. MRCP of bile and pancreatic duct abnormalities with emphasis on the single-shot fast spinecho technique. Radiographics. 2000;20(4):939-957.

5. Todani T, Urushihara N, Morotomi Y, Watanabe Y, Uemura S, Noda T, et al. Characteristics of choledochal cysts in neonates and early infants. Eur J Pediatr Surg. 1995;5(3):143-145.

6. de Vries JS, de Vries S, Aronson DC, Bosman DK, Rauws EA, Bosma A, et al . Choledochal cysts: age of presentation, symptoms, and late complications related to Todani's classification. J Pediatr Surg. 2002;37(11):1568-1573.

7. Mishra A, Pant N, Chadha R, Choudhury SR. Choledochal cyst in infancy and childhood. Indian J pediatr. 2007;74(10):937-942

8. Lee HC, Yeung CY, Chang PY, Sheu JC, Wang NL. Dilatation of the biliary tree in children: sonographic diagnosis and its clinical significance. J Ultrasound Med. 2000;19(3):177-182.

9. Jordan PH, Goss JA, Rosenberg WR, Woods KL. Some considerations for management of choledochal cyst. Am J Surg. 2004;187(3):434-439.

10. Hua MC, Chao HC, Lien R, Lie JY, Lai M, Kong MS. The Different Clinical and Liver Pathological Characteristics between the New borns and Infants with Choledochal Cysts . Chang Gung Med J. 2009;32(2):198202.

11. Moyer V, Freese DK, Whitington PF, Olson AD, Brewer F, Colletti RB, et al . Guideline for the evaluation of cholestatic jaundice in infants: recommendations of the North American Society for Pediatric Gastroenterology, Hepatology and Nutrition. J Pediatr Gastroenterol Nutr. 2004;39(2):115-128.

12. Lin WY, Lin CC, Changlai SP, Shen YY, Wang SJ. Comparison technetium of Tc-99m disofenin cholescintigraphy with ultrasonography in the differentiation of biliary atresia from other forms of neonatal jaundice. Pediatr Surg Int. 1997;12(1):30-33.

13. Nadel HR. Hepatobiliary scintigraphy in children. Semin Nucl Med. 1996;26(1):25-42.

14. Gupta DK, Srinivas M, Bajpai M. AIIMS Clinical score: a reliable aid to distinguish neonatal hepatitis from extra hepatic biliary atresia. Indian J Pediatr. 2001;68(7):605-608.

15. Brugge WR, Van Dam J. Pancreatic and biliary endoscopy. NEJM. 1999;341:1808-1816. DOI: 10.1056/NEJM199912093412406

16. Kim JH, Kim MJ, Park SH, Chung JJ, Song SY, Kim KS, et al. MR cholangiography in symptomatic gallstones: diagnostic accuracy according to clinical risk group. Radiology. 2002;224(2):410-416.

17. Sudha AA . Pancreatic and biliary anomalies. Paediatr Radiol. 2008;38:267-S271.

18. Sugiyama M, Baba M, Atomi Y, Hamaoka H, Mizutani Y, Hailiya J. Diagnosis of anomalous pancreaticobiliary junction: value of MRCP. Surgery. 1998;123(4):391-397.

19. Hirohashi S, Hirohashi R, Uchida H, Akira M, Itoh T, Haku E, et al. Pancreatitis: Evaluation with MRCP in children. Radiology. 1997:203:41115.

20. Kamisawa T, Tu Y, Egawa N, Tsuvuta K, Okamoto A, Kamala N. MRCP of congenital pancreaticobiliary malformation. Abdom Imaging. 2007;32(1):129-133.

21. Lai MW, Chang MH, Hsu SH, Su CT, Kao CL, Lee CY. Differential diag- 
nosis of EHBA from neonatal hepatitis: a prospective study. J Pediatr Gastroenterol Nutr. 1994;18(2):121-127.

22.Jaw TS, Kuo YT, Liu GC, Chen SH, Wang CK. MRCP in the evaluation of neonatal cholestasis. Radiology. 1999;212:249-256.

23. Matos C, Nicaise N, Deviere J, Cassart M, Metens T, Struyven J, et al. Choledochal cyst: comparison of findings at MR cholangiopancreatography and endoscopic retrograde cholangiopancreatography in eight patients. Radiology. 1998;209(2):443-448.

24. Norton KI, Glass RB, Kogan D, Lee JS, Emre S, Shneider BL. MR Cholangiography in the evaluation of neonatal cholestasis: initial results. Radiology. 2002;222(3):687-691.

25. Fulcher AS, Turnce MA, Capps GW. MRCP technical advances and clinical applications. Radiographics. 1999;19:25-41.

26. Delaney L, Applegate KE, Karmazn B, Akisik MF, Mennings SG. MRCP in children: feasibility, safety and initial experience. Pediatr Radiol. 2008;38(1):64-75.
27. Miyazaki T, Yamashica Y, Tang Y, Tsuching, Ame T, Takahashi M, et al. Single shot MRCP of neonates, infants and young children. Am J Roentgenol. 1998;170(1):33-37.

28. Meyer S, Gottschling S, Georg T, Lothschu D, Graf N, Sitzmann FC, et al. Gammahydroxybutyrate versus chlorprothixene/phenobarbital sedation in children undergoing MRI studies. Klin Padiatr. 2003;215(2):69-73.

29. Schulte UL, Goepfert MS. Anaesthesia or sedation for MRI in children. Curr Opin Anaesthesiol. 2010;23(4):513-517. doi: 10.1097/ AC0.0b013e32833bb524

30. Maitre NL, Smolinsky C, Slaughter JC, Stark AR. Adverse neurodevelopmental outcomes after exposure to phenobarbital and levetiracetam for the treatment of neonatal seizures. J Perinatol. 2013;33(11):841846. doi: $10.1038 /$ jp.2013.116 